\title{
Surface Properties of Oxidized and Aminated Multi-Walled Carbon Nanotubes
}

\author{
Wellington M. Silva, ${ }^{a}$ Hélio Ribeiro, ${ }^{a}$ Luciana M. Seara, ${ }^{b}$ Hállen D. R. Calado, ${ }^{a}$ \\ André S. Ferlauto, ${ }^{c}$ Roberto M. Paniago, ${ }^{c}$ Cristiano F. Leite ${ }^{c}$ and Glaura G. Silva ${ }^{*, a}$ \\ ${ }^{a}$ Departamento de Química and ${ }^{c}$ Departamento de Física, Instituto de Ciências Exatas, \\ Universidade Federal de Minas Gerais, 31270-901 Belo Horizonte-MG, Brazil
}

${ }^{b}$ Centro de Microscopia,Universidade Federal de Minas Gerais, 31270-901 Belo Horizonte-MG, Brazil

\begin{abstract}
A influência de modificação química (por tratamento ácido seguido de funcionalização com trietilenotetramina, TETA) sobre a superfície de nanotubos de carbono de paredes múltiplas (MWCNT) foi estudada qualitativa e quantitativamente. A análise termogravimétrica (TGA) mostrou que, no caso do nanotubo funcionalizado com amina, $29 \%$ de perda de massa pode ser atribuída a $-\mathrm{C}(=\mathrm{O})$ TETA e grupos funcionais residuais que contêm oxigênio. A espectroscopia de fotoelétrons excitados por raios X (XPS) foi utilizada para observar as funções aminadas e oxigenadas ligadas covalentemente à superfície do nanotubo. As imagens de microscopia de força elétrica (EFM) indicaram que, à medida que se modifica a química superficial dos nanotubos em presença de ar, estes mostram respostas diferentes em função do potencial da ponta. Deslocamentos nos sinais de fase de EFM decrescem quando se modifica a superfície dos tubos com grupos funcionais contendo oxigênio e amina. Em atmosfera seca e inerte de $\mathrm{N}_{2}$, as três diferentes superfícies mostraram a mesma resposta à EFM. Além disso, o caráter hidrofílico dos "buckypapers" cresceu na ordem MWCNT < MWCNT-aminado < MWCNT-oxidado.
\end{abstract}

The influence of chemical modification by acid treatment followed by triethylenetetramine (TETA) functionalization on the surface of multi-walled carbon nanotubes (MWCNT) was evaluated, both qualitative and quantitatively. Thermogravimetric analysis (TGA) showed that, in the case of amine-functionalized nanotubes, $29 \%$ of mass loss can be attributed to $-\mathrm{C}(=\mathrm{O})$ TETA and residual oxygen-containing functional groups. X-ray photoelectron spectroscopy (XPS) was used to observe the oxygenated and aminated functions covalently linked to the nanotube surface. Electric force microscopy (EFM) images indicated that the nanotubes with diverse surface chemistry showed distinct responses to the tip potential in the presence of air. Shifts in EFM phase images decreased when the nanotube surface was modified with oxygen and amine-containing functional groups. In dry and inert $\mathrm{N}_{2}$ atmosphere, however, the three different surfaces showed the same response to EFM. In addition, the hydrophilic character of the buckypapers increased in the order MWCNT < aminated-MWCNT < oxidized-MWCNT.

Keywords: multi-walled carbon nanotubes, triethylenetetramine, surface chemical modification, spectroscopic characterization, electric force microscopy

\section{Introduction}

An important historical reference about carbon nanotube (CNT) synthesis is the work of Oberlin et al. in $1976 .{ }^{1}$ However, it was not until Iijima's work, in $1991,{ }^{2}$ that CNTs emerged as a key material in the field of nanotechnology due to their extraordinary thermal, electrical and mechanical properties. ${ }^{2-4}$ However,

*e-mail: glaura@qui.ufmg.br low dispersibility in organic and inorganic solvents, combined with poor chemical compatibility, has become a major issue. ${ }^{5,6}$ Functionalization or chemical modification of CNT, that is, the covalent attachment of atoms or molecules to the surface, has been used to introduce chemical specificity and processability in different environments. The effects of acid treatment on the structure and morphology of the tubes have been described in depth in previous studies. ${ }^{7-12}$ Methods based on carboxylation present advantages in that CNT can be 
derivatized through covalent modifications to esters or amides through different preparation routes. ${ }^{13,14}$

Currently, CNT functionalized with amine groups are widely used in high-performance composites and biological studies. ${ }^{6}$ However, the functionalization with TETA has not been described as in depth as the processes based on other amines such as octadecylamine (ODA), ethylenediamine and aniline.${ }^{14-19}$ Using acid oxidation and post reaction with $\mathrm{SOCl}_{2}$, Wang et al. ${ }^{20}$ functionalized MWCNT $(\varnothing=20-80 \mathrm{~nm})$ with TETA and modified the composites using the epoxy resin DGEBA (bisphenol A-epichlorohydrin E-44) as a polymeric matrix. Chemical modifications in the structure of the tubes were observed with Fourier-transform infrared spectroscopy (FTIR) and an increase of $14.5^{\circ} \mathrm{C}$ in the glass transition temperature $\left(\mathrm{T}_{\mathrm{g}}\right)$ of the composites with $0.5 \mathrm{wt} \%$ of functionalized MWCNT was found using dynamic mechanical analysis (DMA). Applying a similar chemical modification procedure, Yang et al. ${ }^{21}$ observed the formation of a homogenous dispersion in epoxy resin, which indicated a strong interaction between nanotubes and polymer. This strong interaction resulted in an $84 \%$ increase on the impact-resistant module in composites containing $0.6 \mathrm{wt} \%$ of MWCNT functionalized with TETA.

Recently, other carbon forms have also been modified with TETA. As an example, activated carbons have been treated by alternative processes in order to improve their chemical and mechanical properties. ${ }^{22,23}$ Also, chemical functionalization routes of MWCNT using different amines and activators such as $N, N, N^{\prime}, N^{\prime}$-tetramethyluroniumhexafluorophosphate ( $N$-HATU) have been used in biological studies. Vukovic et $\mathrm{al} .{ }^{24}$ evaluated the cytotoxicity of MWCNT functionalized with different amines against fibroblast cells. They showed that functionalized MWCNT are not cytotoxic at concentrations of $1-50 \mu \mathrm{g} \mathrm{mL}^{-1}$;

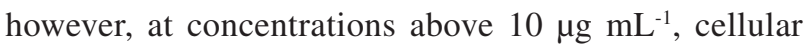
growth was reduced.

In this study, the structural properties of functionalized MWCNT were evaluated after each stage of the chemical modification process, and the presence of amide groups formed upon the covalent attachment of TETA to carbonyl carbons on the CNT surface was fully characterized. Detailed studies involving Fourier-transform infrared spectroscopy (FTIR), Raman spectroscopy, thermogravimetric analysis (TGA), X-ray photoelectron spectroscopy (XPS), degree of hydrophilicity and transmission electron microscopy (TEM) were performed in order to characterize the chemical modifications that were introduced along the tubes. Furthermore, electric force microscopy (EFM) was applied to assess the surface properties. EFM is a powerful technique for the study of electrical properties of nanosized objects and has enabled insights into the electrical behavior, charge distribution and functionalities of these nanomaterials. ${ }^{25-28}$

EFM is a dual-pass technique that employs a conductive tip oscillating at its resonance frequency above the surface. A DC bias is applied between the tip and the sample. In the first step, in which the topographic line scan is recorded, the short-range van der Waals forces dominate the tip response. In the second scan, the tip is lifted to a defined height above the surface and replicates the height profile, keeping the tip-surface distance (and the van der Waals interactions) constant. The presence of localized charges on the surface induces long-range Coulombic forces that dominate the tipsurface interactions. The resultant force gradient perturbs the cantilever's effective spring constant, its resonance frequency and, in-turn, the phase lag between the drive and the cantilever response. From this mechanism, both the phase and frequency shift can be recorded as an EFM signal. Monitoring the phase shift provides contrast image in areas where the conductivity varies, giving qualitative information on the local charge distribution. Moreover, if a feedback loop is introduced to stabilize the phase shift, the EFM signal can be rationalized as a shift in the excitation frequency to maintain the phase shift. ${ }^{27,29,30}$

\section{Experimental}

\section{Materials}

The MWCNT were synthesized from xylol by chemical vapor deposition (CVD). They were grown as carpets approximately $3 \mathrm{~mm}$ high with an external diameter between 50 and $100 \mathrm{~nm}$ and a purity of approximately $95 \%$ in mass. The commercial product D.E.H. 24 (TETA-based), supplied by the company Akzo Nobel, was used as a functionalization agent.

\section{Methods}

The oxidation and functionalization reactions are shown schematically in Figure 1, which, for simplification, indicates only the functionalization involving carboxyl groups. Before the functionalization with TETA, an acid treatment with a $3: 1$ mixture of $\mathrm{H}_{2} \mathrm{SO}_{4} / \mathrm{HNO}_{3}$ allowed the introduction of carboxyl groups (-COOH) onto the surfaces of the tubes. Wepasnick et al. ${ }^{12}$ showed recently that the aggressive oxidants in the mixture $\mathrm{H}_{2} \mathrm{SO}_{4} / \mathrm{HNO}_{3}$ allow the oxygenated functional groups be composed of more than 50 atomic $\%$ of $-\mathrm{COOH}$ functions; the other functional groups in the nanotube surface are $\mathrm{C}=\mathrm{O}$ and $\mathrm{C}-\mathrm{OH}$. The acid mixture was added to $300 \mathrm{mg}$ of MWCNT and refluxed in an ultrasonic bath at a frequency of $40 \mathrm{kHz}$ for $3 \mathrm{~h}$. After 
oxidation, the mixture was centrifuged, filtered in vacuum through a polytetrafluoroethylene membrane with a $0.45 \mu \mathrm{m}$ pore size and then washed until the $\mathrm{pH}$ value was neutral. The solid product was dried in an oven at $100{ }^{\circ} \mathrm{C}$ for $12 \mathrm{~h}$.

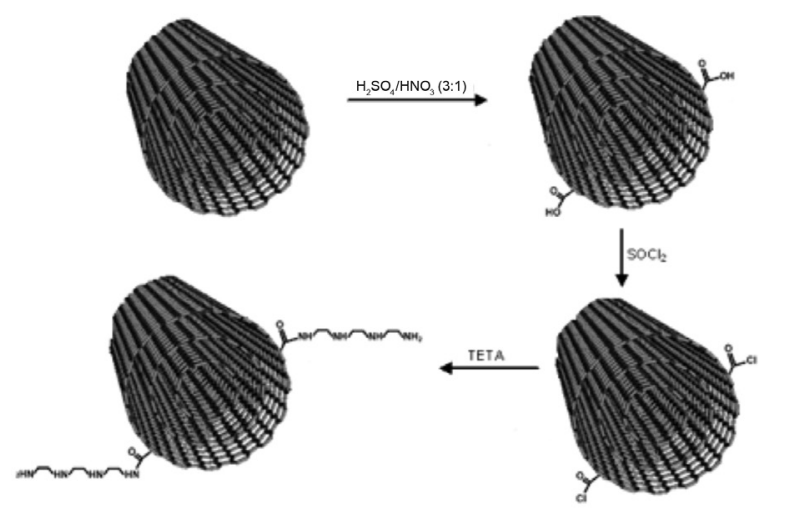

Figure 1. Oxidation and TETA functionalization scheme for MWCNT. Although $\mathrm{C}-\mathrm{OH}$ and $\mathrm{C}=\mathrm{O}$ functionalizations are also present, only the $-\mathrm{COOH}$ functions are showed for simplicity.

For the functionalization, $120 \mathrm{~mL}$ of freshly distilled $\mathrm{SOCl}_{2}$ was added to $300 \mathrm{mg}$ of oxidized MWCNT. The mixture was heated to $70^{\circ} \mathrm{C}$ and kept under reflux for $24 \mathrm{~h}$. After this period, the $\mathrm{SOCl}_{2}$ was extracted by distillation and $120 \mathrm{~mL}$ of TETA were added to the same recipient. The mixture was heated under reflux at $120^{\circ} \mathrm{C}$ for $72 \mathrm{~h}$ and then cooled to room temperature, centrifuged and dispersed in a beaker containing $300 \mathrm{~mL}$ of anhydrous ethanol to remove the TETA adsorbed on the tube walls. The remaining solution was vacuum filtered and extensively washed with anhydrous ethanol. The filtered material was dried in an oven at $100{ }^{\circ} \mathrm{C}$ for $12 \mathrm{~h}$ and denominated as aminated-MWCNT.

Hydrophilicity was evaluated with contact angle measurements using a drop of water on buckypapers. The buckypapers were prepared as follow: with an ultrasonic bath, approximately $150 \mathrm{mg}$ of MWCNT were dispersed in $100 \mathrm{~mL}$ of tetrahydrofuran (THF), while oxidized-MWCNT and aminated-MWCNT were dispersed in $100 \mathrm{~mL}$ of distilled water. The dispersions were filtered and then the films were dried in an oven and removed as self-sustained membranes.

\section{Characterization}

FTIR measurements were performed on a Perkin Elmer System, model Spectrum GX. The spectra were collected from 128 accumulations in the transmission mode and then systematically adjusted, taking base line corrections into account. Micro-Raman measurements were carried out using a DILOR XY-spectrometer equipped with a liquid nitrogen-cooled charge coupled device (CCD). The $514.5 \mathrm{~nm}$ line of an $\mathrm{Ar}-\mathrm{Kr}$ laser was used as the excitation source. The measurements were performed in a backscattering geometry, using an $80 \mathrm{X}$ objective lens. The laser power density was kept below $10^{5} \mathrm{~W} \mathrm{~cm}^{-2}$ to avoid heating effects and to enhance the signal to noise ratio; the spectra represent an average of 10 two-min acquisitions. Spectroscopic manipulations such as baseline adjustment, band component analysis and smoothing were performed using the PEAKFIT 4.0 software.

Thermogravimetric measurements were performed using the equipment SDT 2960 by TA Instruments. The samples were analyzed at a heating rate of $5^{\circ} \mathrm{C} \mathrm{min}^{-1}$ from $30-1000^{\circ} \mathrm{C}$ under an atmosphere of synthetic air flowing at $100 \mathrm{~mL} \mathrm{~min}^{-1}$.

The XPS spectra were obtained at room temperature on a VG Scientific Escalab 220-ixL system. The base pressure in the vacuum chamber was $2.0 \times 10^{-10} \mathrm{mbar}$, and an $\mathrm{Mg}$ anode was used to generate X-rays on the line $\mathrm{K} \alpha(\mathrm{E}=1487 \mathrm{eV})$. Stretched XPS spectra between 0 and $1000 \mathrm{eV}$ were obtained with $1-\mathrm{eV}$ steps, and a high resolution spectrum with $0.1-\mathrm{eV}$ steps was obtained in the peak region of photoemission for $\mathrm{C} 1 \mathrm{~s}, \mathrm{~N} 1 \mathrm{~s}$ and $\mathrm{O} 1 \mathrm{~s}$ electrons. The electron energy analyzer operated in large area mode $(\varnothing=4 \mathrm{~mm}$ ) with a pass energy of $50 \mathrm{eV}$ for stretched spectra and $20 \mathrm{eV}$ for the analysis of individual lines. Each spectrum was adjusted using with a combination of Gaussian and Lorentzian functions.

The hydrophilicity of the buckypapers was evaluated by performing contact angle measurements. A drop of water was placed on the surface of each buckypaper sample, and an image of the drop was captured with a digital camera. The contact angles were calculated with ImageJ.

The TEM images were obtained on a FEI TECNAI G2 microscope with a tungsten filament electron gun of $200 \mathrm{kV}$. The samples were dispersed in propanol for 5 min using an ultrasonic bath. After the dispersion, one drop was placed on a 200 mesh Holey Carbon copper grid.

The EFM analyses were performed on MWCNT and chemically-modified MWCNT (oxidized and aminated) deposited onto a $20 \mathrm{~nm}$ Au-coated Si wafer. A drop of the each nanotube dispersion was deposited onto the clean substrate and dried at $60{ }^{\circ} \mathrm{C}$ to prevent material agglomeration during solvent evaporation. In air, the EFM images were obtained with an Asylum MFP-3D-SA AFM using Pt coated tips (Olympus AC240TM electrilevers). For dry $\mathrm{N}_{2}$, images were obtained using a Nanoscope III - Digital Instruments - equipped with a similar tip. The tip apex radius was $28 \pm 10 \mathrm{~nm}$, the spring constant $0.5-4.4 \mathrm{~N} \mathrm{~m}^{-1}$ and the resonance frequency was $45-95 \mathrm{kHz}$. 
In air, the images were generated by varying, in the same region, the tip voltage $( \pm 1.5 \mathrm{~V}$ and $\pm 3 \mathrm{~V})$ and, for each voltage, the lift height $(20,30,40$ and $50 \mathrm{~nm})$. For the experiments in $\mathrm{N}_{2}$, EFM was carried out using a $\pm 1.5 \mathrm{~V}$ tip voltage and a life height of $400 \mathrm{~nm}$.

\section{Results and Discussion}

FTIR and Raman spectroscopy were used to investigate the chemical structure of the MWCNT samples. The results (Figure S1) and discussion related to the FTIR analysis are presented as Supplementary Information (SI).

Figure 2 shows the Raman spectra of the MWCNT as received (Figure 2a), oxidized-MWCNT (Figure 2b) and aminated-MWCNT (Figure 2c). Five measurements were performed in different regions of the samples to provide representative results. Data presented in Table 1 represent the average of these measurements.

There are three distinct peaks in all spectra. The first is the D band, which is induced by structural disorder of the tubes and is identified at 1347,1348 and $1350 \mathrm{~cm}^{-1}$ for MWCNT, oxidized-MWCNT and aminated-MWCNT respectively, as shown in Table 1 . The second peak, the $\mathrm{G}$ band, is associated with the tangential stretching mode of the graphite $\mathrm{C}=\mathrm{C}$ bond; it is located at 1573,1574 and $1575 \mathrm{~cm}^{-1}$ for MWCNT, oxidized, and aminated nanotubes, respectively. ${ }^{34}$ The third contribution appears in the spectra as a shoulder of the G-band at the high frequency side. This feature, observed at $1609 \mathrm{~cm}^{-1}$ for MWCNT and oxidized-MWCNT and $1612 \mathrm{~cm}^{-1}$ for the aminated nanotube (see Table 1), is denominated as the D' band, and, similarly to the D band, the D' band is originated from a double resonance Raman process induced by structural disorder. ${ }^{35,36}$ Thus, the intensities of the D (ID) and D' (ID') bands are associated with the presence of defects on the nanotubes, while the G band intensity (IG) must be independent of structural disorder.

The oxidation process creates defects on the nanotube surface and in this case the ratios ID/IG and ID'/IG are expected to increase. However, no significant change in the ID/IG ratio is observed in the Raman spectra as shown in Table 1; the small changes observed, from ID/IG $=0.84$ to 0.93 and 1.07, are lower than the standard error of the

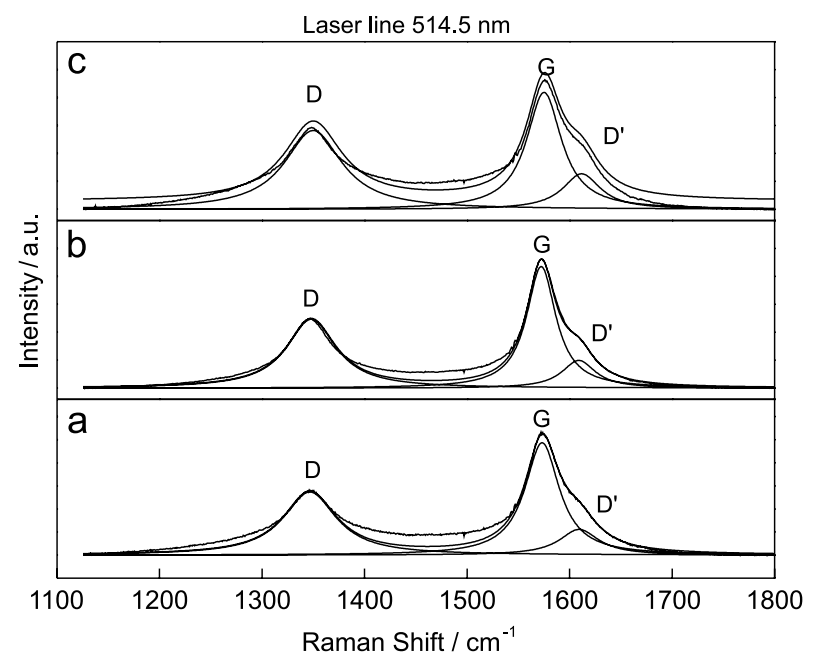

Figure 2. Raman spectra for a) MWCNT, b) oxidized-MWCNT and c) aminated-MWCNT. The $514.5 \mathrm{~nm}$ line of an $\mathrm{Ar}-\mathrm{Kr}$ laser was used as the excitation source.

measurements. We can see in the figures that the D band is very intense, which is typical of MWCNT samples. Thus, the amount of defects created during the oxidation and functionalization processes is not high enough to generate a significant increase in the ID/IG ratio or a significant increase in the Raman band linewidth (FWHM) for the MWCNT employed in this study.

The ID/IG values in Table 1 are similar to the results reported by Yang et al. ${ }^{21}$ Moreover, the ID/IG ratio for the optimized carboxylated sample reported by those authors is close to the one obtained for the aminated-MWCNT in the present work. Yang et al. ${ }^{21}$ did not report results for the TETA-modified MWCNT sample.

Due to their thermal instability, functional groups produced by the oxidation and functionalization processes decompose at temperatures below $400{ }^{\circ} \mathrm{C} .{ }^{7,8,24,34}$ Figure 3 presents the curves corresponding to the mass loss as a function of temperature (Figure 3a) and the derivative of the TGA curve (DTG) (Figure 3b). The thermogram in Figure 3a shows only one stage of decomposition for the MWCNT sample at temperatures between 450 and $650{ }^{\circ} \mathrm{C}$, which is a typical result for a MWCNT. ${ }^{37}$ For the functionalized samples, the loss of mass due to the oxidation of the functional groups occurs under $400{ }^{\circ} \mathrm{C}$ and at variable temperatures due to the different functional

Table 1. Raman spectral positions

\begin{tabular}{|c|c|c|c|c|c|c|}
\hline & MWCNT & FWHM & Oxidized-MWCNT & FWHM & Aminated-MWCNT & FWHM \\
\hline $\mathrm{D}$ band $/ \mathrm{cm}^{-1}$ & $1347.0 \pm 0.9$ & 63 & $1348.0 \pm 0.7$ & 58 & $1350.0 \pm 0.7$ & 68 \\
\hline $\mathrm{G}$ band $/ \mathrm{cm}^{-1}$ & $1573.0 \pm 1.5$ & 41 & $1574.0 \pm 0.5$ & 35 & $1575.0 \pm 1.1$ & 42 \\
\hline $\mathrm{D}^{\prime}$ band $/ \mathrm{cm}^{-1}$ & 1609 & 46 & 1609 & 40 & 1612 & 45 \\
\hline ID/IG & 0.84 & - & 0.93 & - & 1.07 & - \\
\hline
\end{tabular}


groups placed on the tube surface. When the DTG curve is checked (Figure 3b), these decompositions are clearly identified. The broad mass loss for the oxidized-MWCNT at temperatures of up to $400{ }^{\circ} \mathrm{C}$ (maximum at $315^{\circ} \mathrm{C}$ ) is associated to the decomposition of the various oxygenated groups (17\%). The decomposition of the functional groups for the aminated-MWCNT occurs at $295{ }^{\circ} \mathrm{C}(29 \%)$ and can be associated with the decomposition of TETA-based groups and residual oxygenated groups that did not react with TETA.
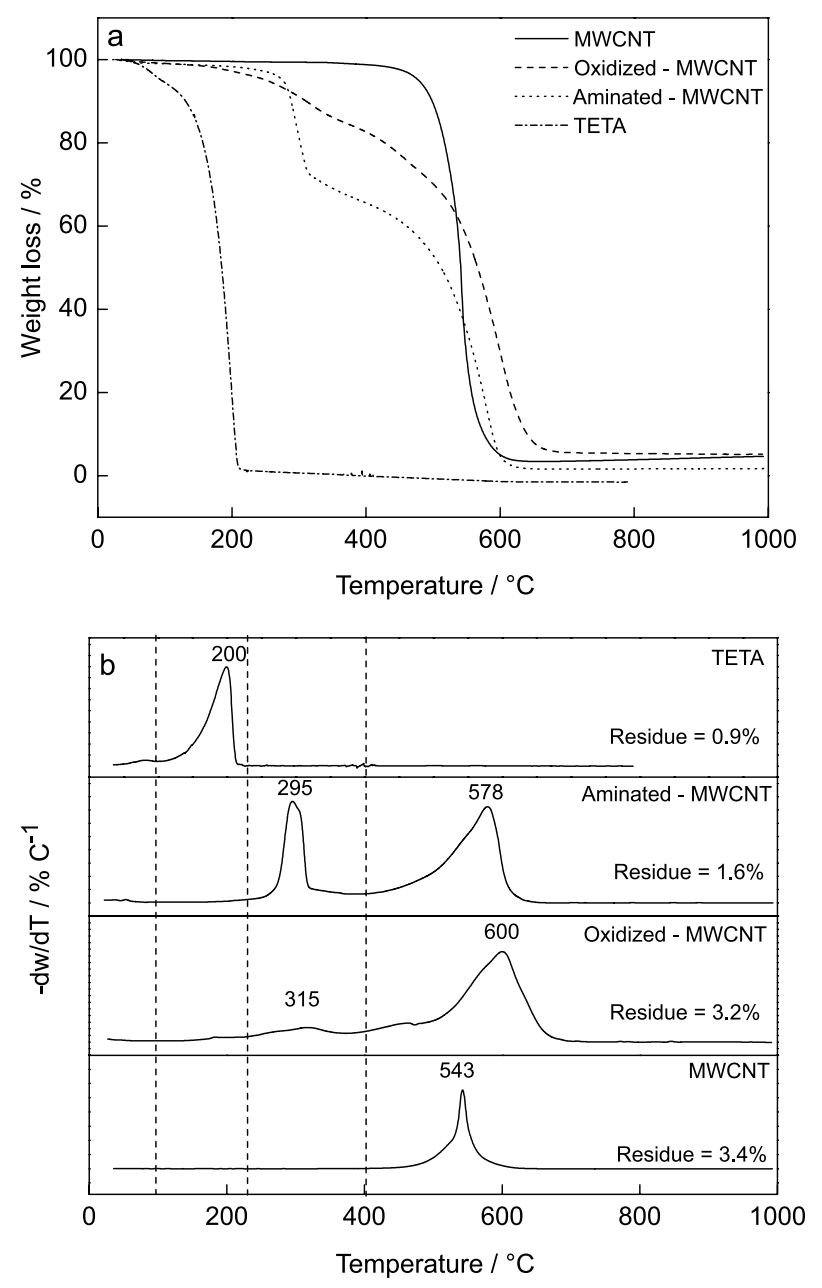

Figure 3. TGA (a) and DTG curves (b) for MWCNT, oxidized-MWCNT, aminated-MWCNT and TETA.

XPS spectra were obtained in the regions of the main elements of interest $(\mathrm{C}, \mathrm{O}$ and N). Figure S2 (Supplementary Information) shows the survey XPS spectra of the MWCNT, oxidized-MWCNT and aminatedMWCNT samples. All samples show photoemission peaks for $\mathrm{C} 1 \mathrm{~s}(284.5 \mathrm{eV})$ and $\mathrm{O} 1 \mathrm{~s}(532.0 \mathrm{eV})$. The $\mathrm{N} 1 \mathrm{~s}$ $(400.0 \mathrm{eV})$ peak is only observed in the TETA-modified MWCNT spectra. An increase in the intensity of the $\mathrm{O} 1 \mathrm{~s}$ peak and a decrease in the intensity of the $\mathrm{C} 1$ s peak were verified in comparison with the MWCNT sample after each stage of the chemical processing (Figure S2).

The presence of an amide carbonyl was identified in the spectrum of $\mathrm{N} 1 \mathrm{~s}$ (Figure 4), as well as in the XPS spectra in the $\mathrm{C}$ and $\mathrm{O}$ regions, as discussed in the Supplementary Information (Figure S3). After adjustments of the photoemission peaks (Figure 4), three significant contributions with bonding energies from 400.0-402.6 eV were identified. In this case, the atoms of nitrogen with a bonding energy of $400.0 \mathrm{eV}$ are related to the bonds involving primary amines $\left(-\mathrm{CH}_{2}-\mathrm{NH}_{2}\right)$. Yang et al. ${ }^{21}$ assigned the peak at $400.0 \mathrm{eV}$ to nitrogen bonds related to $\mathrm{N}-\mathrm{C}=\mathrm{C}$ groups, but those authors proposed a TETA structure with $\mathrm{C}=\mathrm{C}$ bonds, which is not the recognized chemical structure for this molecule with an IUPAC name of $N, N^{\prime}$-bis(2-aminoethyl)ethane-1,2-diamine $\left(\left[\mathrm{CH}_{2} \mathrm{NHCH}_{2} \mathrm{CH}_{2} \mathrm{NH}_{2}\right]_{2}\right)$. Atoms of nitrogen with bonding energies at $401.0 \mathrm{eV}$ are only bonded to amide carbonyl groups $(-\mathrm{N}-\mathrm{C}=\mathrm{O})$, and atoms of nitrogen with bonding energies at $402.6 \mathrm{eV}$ are related to bonds involving secondary amines $\left(-\mathrm{CH}_{2}-\mathrm{NH}-\mathrm{CH}_{2}-\right) .{ }^{19}$

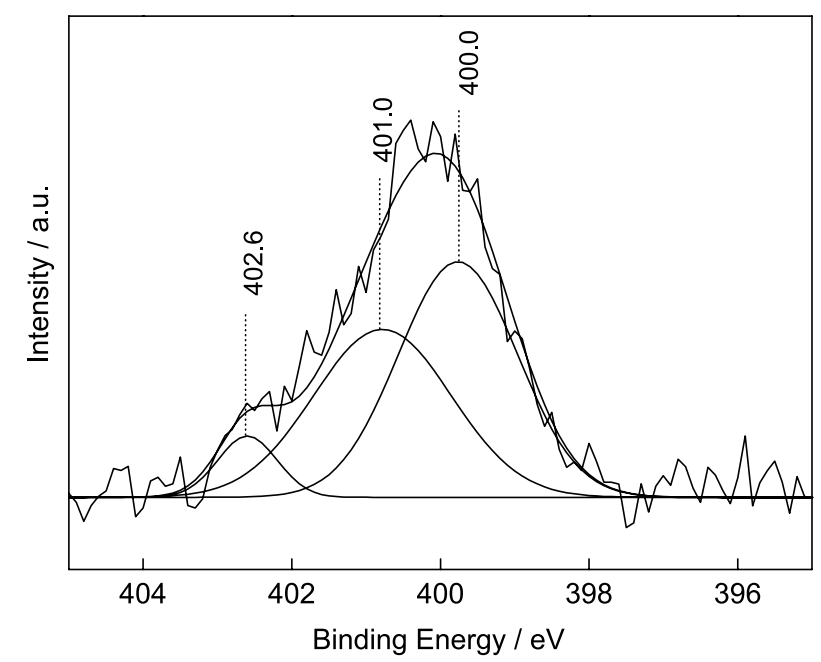

Figure 4. High resolution XPS spectra obtained in the $\mathrm{N}$ 1s bonding energy region for aminated-MWCNT.

The hydrophilicity of the samples was evaluated through the variations of the contact angle of a drop of water placed on the surface of the buckypapers as presented in Figure 5.

Figure 5a shows that the contact angle of the drop of water on the buckypaper film is $90^{\circ}$. MWCNT is mostly constituted by hydrophobic carbon atoms with $\mathrm{sp}^{2}$ hybridization. After the processes of oxidation and TETA functionalization, the functional groups introduced onto the tube walls caused a change in the contact angle of the water drop due to hydrogen bonding interactions. For the oxidized sample (Figure $5 b$ ), the contact angle is 

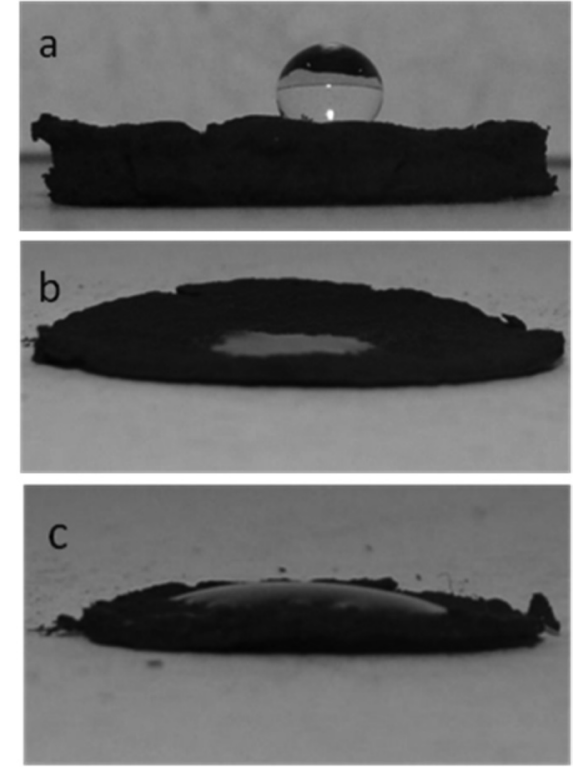

Figure 5. Variation of the water contact angle on buckypaper surfaces for samples based on a) MWCNT, b) oxidized-MWCNT and c) aminatedMWCNT.

practically zero, being $\mathrm{ca} .20^{\circ}$ for the sample functionalized with TETA (Figure 5c). It is interesting to note that, although the functionalization did not cause significant modifications in the data obtained from the Raman spectra, the hydrophilicity on the nanotubes' surface changed dramatically.

The surface textures of the "as-received" and chemically processed MWCNT are shown in the TEM images of Figure 6.
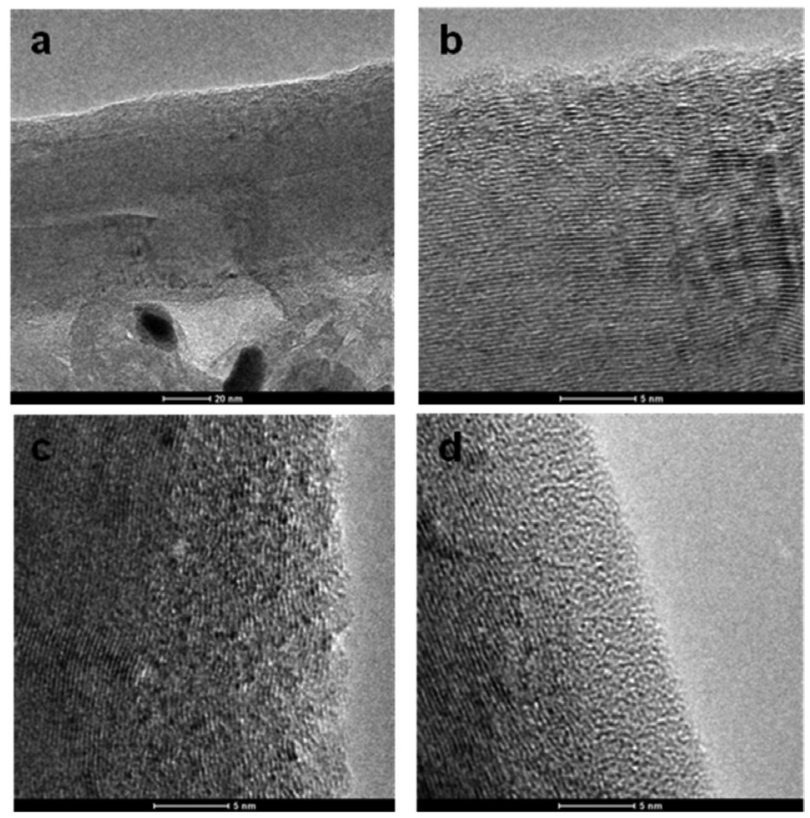

Figure 6. TEM typical images of a) MWCNT, b) MWCNT, c) oxidizedMWCNT and d) aminated-MWCNT.
Figure 6a shows that there are two darker regions in the structure of the MWCNT, indicating the presence of impurities due to the synthetic process. Such impurities were identified through XPS (Supplementary Information) as being particles of $\mathrm{Fe}_{2} \mathrm{O}_{3}$ and $\mathrm{Al}_{2} \mathrm{O}_{3}$. Following acid treatment, these impurities were removed. ${ }^{10} \mathrm{It}$ is important to note that the external walls of the MWCNT samples (Figure 6b) are structurally more organized than the ones from the oxidized-MWCNT sample (Figure 6c). After the functionalization with TETA (Figure 6d), the formation of a thin layer was observed over the surface of the tubes in the TEM images. ${ }^{21}$

One remaining question is how to evaluate the functionalization distribution of oxygenated and amine groups on the MWCNT surface. In this context, EFM was applied to give insights on functionalization along the tubes. EFM has been used mainly to probe electric characteristics of single-walled and multi-walled carbon nanotubes..$^{40-42}$

Figure 7 shows the topographic images (top) of MWCNT, oxidized-MWCNT and aminated-MWCNT and the corresponding phase images of the lift mode (bottom). The mean diameters are $58 \mathrm{~nm}, 70 \mathrm{~nm}$ and $48 \mathrm{~nm}$ for MWCNT, oxidized-MWCNT and aminated-MWCNT, respectively. All images shown in the Figure 7 were made under the same conditions, i.e., $1.5 \mathrm{~V}$ and $40 \mathrm{~nm}$ in lift height in air. In the phase images the nanotubes appear in dark shades, corresponding to a negative phase shift due to an attractive tip-sample interaction as observed in other works. ${ }^{27,43-45}$ The TETA-modified MWCNT showed no contrast in phase image for any of the two voltages tested $( \pm 1.5$ and $\pm 3 \mathrm{~V})$.

In comparing the oxidized and aminated nanotubes to the untreated nanotube, the decrease in phase image contrast for the lift mode in air (Figure 7 bottom) may be explained as follows: (i) the presence of $\mathrm{COOH}$ and TETA functional groups may be shielding the external surface of the nanotube. Since TETA is larger than the $\mathrm{COOH}$ group, its shielding effect would be more evident, resulting in a lower contrast; (ii) moisture on the hydrophilic oxidized- and aminated-MWCNTs (as compared to the hydrophobic as-prepared MWCNTs) may be altering the signal. As Figure 5 clearly demonstrates, the functionalized nanotubes are covered with more moisture than the asprepared nanotube when the materials are exposed to air. Therefore, oxidized and aminated MWCNT surfaces may be more electrically conductive, and able to neutralize static charges present on the surface of the tubes more easily than the untreated MWCNT.

The buckypaper hydrophilicity is actually higher for the oxidized nanotube (Figure 5); therefore, the absence of contrast observed in Figure 7c for the aminated-MWCNT 


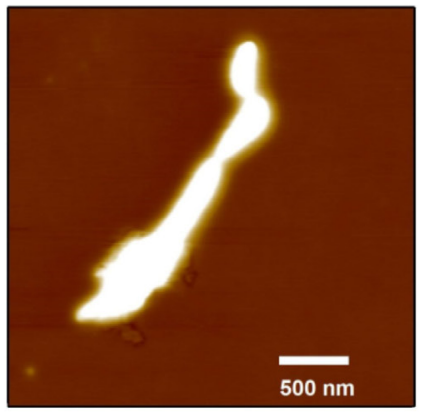

a

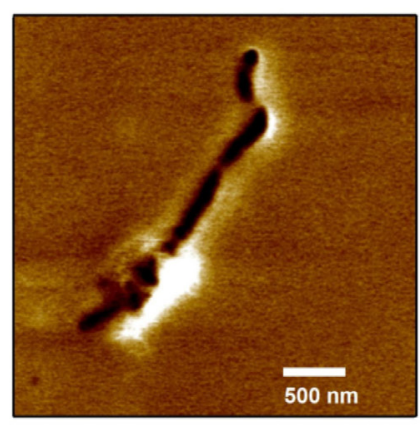

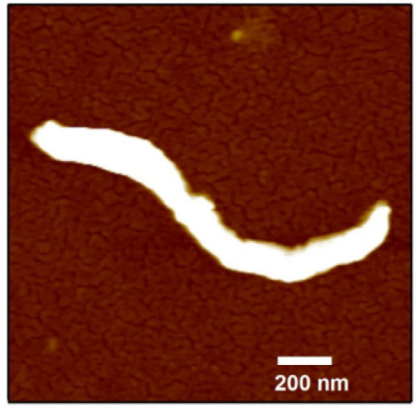

b

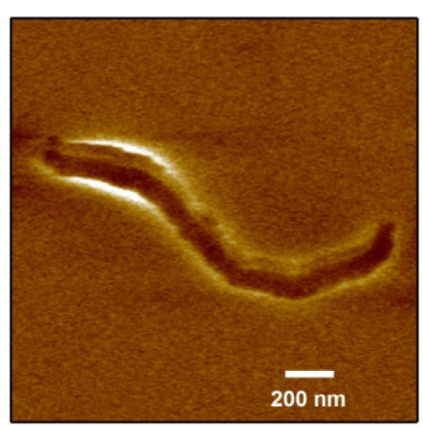

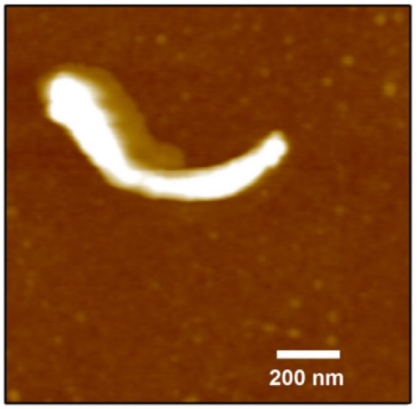

C

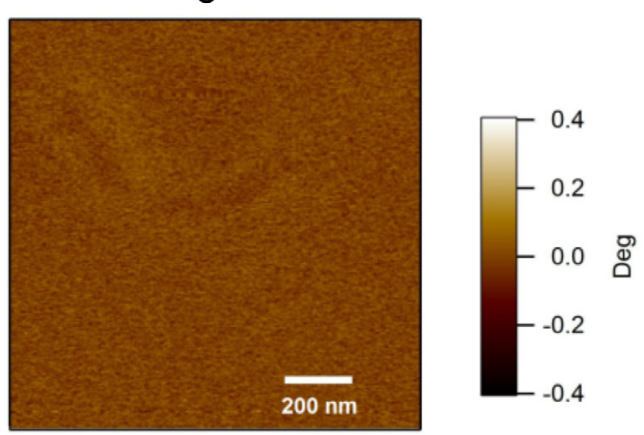

Figure 7. EFM topographic (top) and corresponding EFM phase images (bottom) in air for a) MWCNT b) oxidized-MWCNT and c) aminated-MWCNT. All the topographic images are at the same height scale and all the EFM phase images are at the same phase scale.

can be attributed to the combined effect of moisture and TETA screening.

For a given region of the nanotubes' image, the negative shift for the MWCNT and oxidized-MWCNT samples can be measured and, obviously, no shift for the aminatedMWCNT sample can be determined. The average shift in EFM phase for the acid-treated MWCNT was about 75\% lower in intensity than that for the MWCNT. The shifts were obtained by taking in the images of Figure $7 \mathrm{a}$ and $7 \mathrm{~b}$ the values at ten different points along the tubes. Values very close to those were found in other similar images analyzed.

The capacitive signal is visible for MWCNT and oxidized MWCNT in Figure 7 surrounded by bright features. This could be related to residual trapped charges around the tube. This bright effect in the signal is even more intense for images obtained at negative tip bias, and may be a result of positive charges covering the nanotubes.

Since moisture in the air will affect the properties of carbon nanotubes for several practical applications, the EFM study in air is relevant. However, it is also important to obtain information by EFM in an inert environment. Therefore, the EFM study was repeated using an environment of dry $\mathrm{N}_{2}$. In these experiments, the EFM signal was presented as shifts in the resonant frequency of the tip (Figure 8).

The nanotubes were highly charged, and a signal was observed even at $800 \mathrm{~nm}$ of lift height, a distance much larger than the diameter of the nanotubes. The mean diameters determined in the images of Figure 8 are $95 \mathrm{~nm}$, $118 \mathrm{~nm}$ and $152 \mathrm{~nm}$ for MWCNT, oxidized-MWCNT and aminated-MWCNT, respectively. A lift height of $400 \mathrm{~nm}$ provided the optimal conditions for experiments in dry $\mathrm{N}_{2}$. A series of tests were performed, and a contrast image (due to a frequency shift) as a function of applied voltage was obtained for all nanotube samples.

In contrast to the EFM images in air, Figure 8 shows that the images in dry $\mathrm{N}_{2}$ are similar for all MWCNTs. The contrast due to frequency shifts did not show any difference that can be ascribed to the functionalization. The voltage was identical for the previous experiments $(1.5 \mathrm{~V})$ and opposite bias $(-1.5 \mathrm{~V})$ was used. There were no noticeable differences in the frequency shifts with opposite bias as well.

A comparison of the two EFM experiments revealed the effect of the environment on the electrical properties of the carbon nanotubes: in air (Figure 7) and in dry $\mathrm{N}_{2}$ (Figure 8). We can confirm that moisture in the air was a major factor that contributed to the decrease in EFM signal for the functionalized nanotubes.

It is important to note that for the several EFM images analyzed in both atmospheres, there was no evidence of heterogeneity on the oxygenated or aminated functional groups along the tubes. Therefore, we assert that the oxygenated and aminated groups are well distributed along the tubes, an observation that agrees with the features shown in Figures 7c and 8c. 


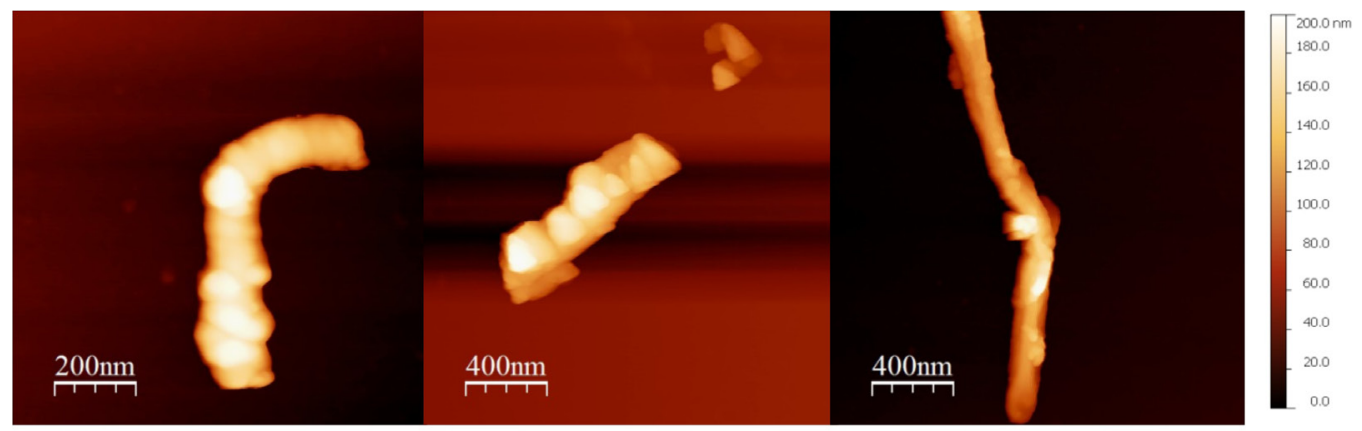

a

b

C

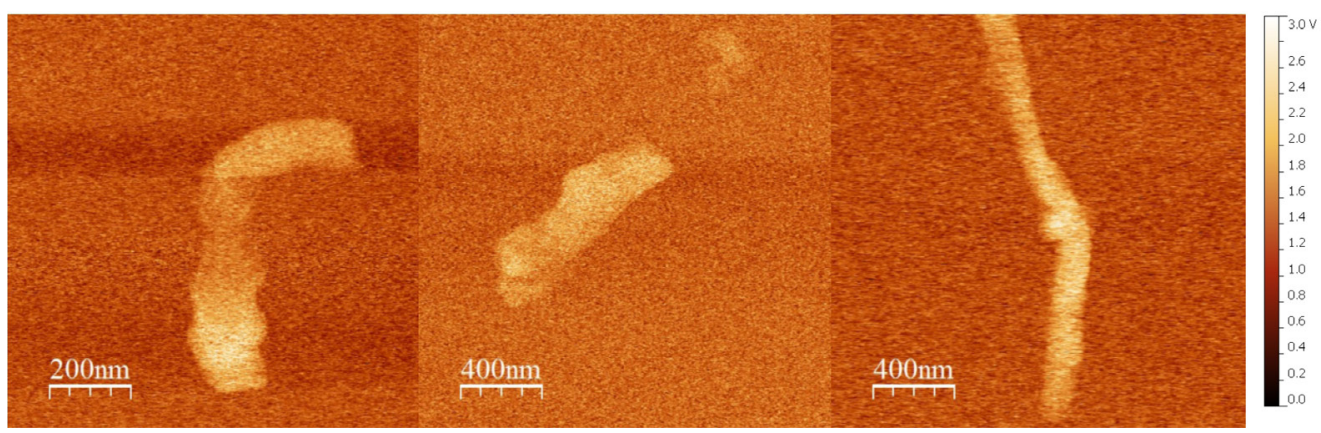

Figure 8. EFM topographic (top) and corresponding EFM frequency images (bottom) in an inert and dry $\mathrm{N}_{2}$ atmosphere for a) MWCNT, b) oxidizedMWCNT and c) aminated-MWCNT. All the topographic images were taken from the same height, and the EFM images utilized the same frequency.

\section{Conclusions}

MWCNT and chemically-modified nanotubes were characterized with respect to the functional groups effect on the surface properties. TGA/DTG results indicate that $17 \%$ of oxygenated functions were added by oxidative treatment. An amount of $29 \%$ was lost in the thermal decomposition close to $295^{\circ} \mathrm{C}$ in the case of the amine-functionalized sample, which corresponds to the $-\mathrm{C}(=\mathrm{O}) \mathrm{TETA}$ and residual oxygenated moieties. The XPS peaks indicated the presence of an amide $-\mathrm{N}-\mathrm{C}=\mathrm{O}$ bond. Important changes in hydrophilicity of the MWCNT functionalized with acid and amine groups were observed. The EFM images support the assertion that these functional groups homogeneously distribute along the tube surface, and that environmental conditions strongly influence the EFM results. The moisture adsorbed to the nanotube surfaces during the tests in air decreased the contrast in the EFM signal for functionalized nanotubes, an effect that was not observed for testing in a dry $\mathrm{N}_{2}$ atmosphere.

\section{Acknowledgments}

This research was supported by Petrobras. Wellington M. Silva thanks the Brazilian agency CNPq for financial support. The authors are also thankful to Instituto Nacional de Ciência e Tecnologia em Nanomateriais de Carbono, Centro de Microscopia/UFMG and Laboratório Nacional de Luz Síncrotron (LNLS).

\section{Supplementary Information}

Supplementary data (FTIR and XPS spectra for carbon nanotubes and functionalized carbon nanotubes) are available free of charge at http://jbcs.sbq.org.br as PDF file.

\section{References}

1. Oberlin, A.; Endo, M.; Koyama, T.; J. Cryst. Growth 1976, 32 , 335.

2. Iijima, S.; Nature 1991, 354, 56.

3. Jorio, A.; Dresselhaus, M. S.; Dresselhaus, G.; Carbon Nanotubes: Advanced Topics in the Synthesis, Structure, Properties and Applications, $1^{\text {st }}$ ed.; Springer Series in Topics in Applied Physics: New York, 2008.

4. Terrones, M.; Int. Mater. Rev. 2004, 49, 325.

5. Tasis, D.; Tagmatarchis, N.; Bianco, A.; Prato M.; Chem. Rev. 2006, 106, 1105.

6. Spitalsky, Z.; Tasis, D.; Papagelis, K.; Galiotis, C.; Prog. Polym. Sci. 2010, 35, 357.

7. Murphy, H.; Papakonstantinou, P.; Okpalugo, T. I. T.; J. Vac. Sci. Technol., B: Microelectron. Nanometer 2006, 24, 715.

8. Datsyuk, V.; Kalyva, M.; Papagelis, K.; Parthenios, J.; Tasis, D.; Siokou, A.; Kallitsis, I.; Galiotis, C.; Carbon 2008, 46, 833.

9. Kovtyukhova, N. I.; Mallouk, T. E.; Pan, L.; Dickey, E. C.; J. Am. Chem. Soc. 2003, 125, 9761.

10. Hu, H.; Zhao, B.; Itikis, M. E.; Haddon, R. C.; J. Phys. Chem. B 2003, 107, 13838. 
11. Gaspar, H.; Pereira, C.; Rebelo, S. L. H.; Pereira, M. F. R.; Figueiredo, J. L.; Freire, C.; Carbon 2011, 49, 3441.

12. Wepasnick, K. A.; Smith, A. B.; Schrote, K. E.; Wilson, H. K.; Diegelmann, S. R.; Fairbrother, H.; Carbon 2011, 49, 24.

13. Basiuk, E. V.; Basiuk, V. A.; Banuelos, J. G.; Saniger-Blesa, J. M.; Pokrovskiy, V. A.; Gromovoy, T. Y.; Aleksandr, V. M.; Mischanchuk, B. G.; Mischanchuk, B. G.; J. Phys. Chem. B 2002, 106, 1588.

14. Gabriel, G.; Sauthier, G.; Fraxedas, J.; Moreno-Manas, M.; Martinez, M. T.; Miravitlles, C.; Casabó, J.; Carbon 2006, 44, 1891.

15. Yu, J. G.; Huang, K. L.; Yang, Q .; Liu, Y. F.; Physica E 2009, 41, 771 .

16. Yang, Y.; Chen, S.; Xue, Q.; Biris, A.; Zhao, W.; Electrochim. Acta 2005, 50, 3061.

17. Li, N.; Xu, Q.; Zhou, M.; Xia, W.; Chen, X.; Bron, M.; Schuhmann, W.; Muhler, M.; Electrochem. Commun. 2010, 12, 939 .

18. Awasthi, K.; Singh, D. P.; Singh, S. K.; Dash, D.; Srivastava, O. N.; New Carbon Mater. 2009, 24, 301.

19. Ma, P. C.; Mo, S. Y.; Tang, B. Z.; Kim, J. K.; Carbon 2010, 48, 1824.

20. Wang, J.; Fang, Z.; Gu, A.; Xu, L.; Liu, F.; J. Appl. Polym. Sci. 2006, 100, 97.

21. Yang, K.; Gu, M.; Guo, Y.; Pan, X.; Mu, G.; Carbon 2009, 47, 1723.

22. Li, Z.; Xijun, C.; Zhenhua, L.; Qun, H.; J. Mol. Struct. 2010 , 964, 58.

23. Peixian, H.; Wen, Y.; Yang, Y.; Liu, L.; J. Macromol. Sci., Part B: Phys. 2008, 47, 1142.

24. Vukovic, G.; Marinkovic, A.; Obradovic, M.; Radmilovic, V.; Colic, M.; Aleksic, R.; Uskokovic, P. S.; Appl. Surf. Sci. 2009, $255,8067$.

25. Melin, T.; Diesinger, H.; Deresmes, D.; Stievenard, D.; Phys. Rev. B: Condens. Matter Mater. Phys. 2004, 69, 035321.

26. Melin, T.; Diesinger, H.; Deresmes, D.; Stievenard, D.; Phys. Rev. Lett. 2004, 92, 166101.

27. Bhushan, B.; Scanning Probe Microscopy in Nanoscience and Nanotechnology, Springer-Verlag: Heidelberg, 2010, Vol. 14-16.
28. Qiu, X. H.; Qi, G. C.; Yang, Y. L.; Wang, C.; J. Solid State Chem. 2008, 181, 1670.

29. Oliver, R. A.; Rep. Prog. Phys. 2008, 71, 1.

30. Keslareck, A. J.; Costa, C. A. R.; Galembeck, F.; J. Colloid Interface Sci.2002, 255, 107.

31. Zhu, S.; Zhang, H.; Bai, R.; Mater. Lett. 2007, 61, 16.

32. Naseh, M. V.; Khodadadi, A. A.; Mortazavi, Y.; Sahraei, O. A.; Pourfayaz, F.; Sedghi, S. M.; World Acad. Sci., Eng. Technol. 2009, 37, 177.

33. Osorio, A. G.; Silveira, I. C. L.; Bueno, V. L.; Bergmann, C. P.; Appl. Surf. Sci. 2008, 255, 2485.

34. Dresselhaus, M. S.; Dresselhaus, G.; Saito, R.; Jorio, A.; Phys. Rep. 2005, 409, 47.

35. Osswald, S.; Havel, M.; Gogotsi, Y.; J. Raman Spectrosc. 2007, 38, 728.

36. Kim, U. J.; Furtado, C. A.; Liu, X.; Chen, G.; Eklund, P. C.; J. Am. Chem. Soc. 2005, 127, 15437.

37. Trigueiro, J. P. C.; Silva, G. G.; Lavall, R. L.; Furtado, C. A.; Oliveira, S.; Ferlauto, A. S.; Lacerda, R. G.; Ladeira, L. O.; Liu, J. W.; Frost, R. L.; George, G. A.; J. Nanosci. Nanotechnol. 2007, 7, 3477.

38. Yang, D. Q.; Rochett, J. F.; Sacher, E.; Langmuir 2005, 21, 8539.

39. Xia, W.; Wang, Y.; Bergstraszer, R.; Kundu, S.; Muhler, M.; Appl. Surf. Sci. 2007, 254, 247.

40. Barboza, A. P. M.; Gomes, A. P.; Chacham, H.; Neves, B. R. A.; Carbon 2010, 48, 3287.

41. Zdrojek, M.; Heim, T.; Brunel, D.; Mayer, A.; Mélin, T.; Phys. Rev. B: Condens. Matter Mater. Phys. 2008, 77, 033404.

42. Zdrojek, M.; Mélin, T; Boyaval, C.; Stievenard, D.; Jouault, B.; Wozniak. M.; Huczko, A.; Gebicki, W.; Adamowicz, L.; Appl. Phys. Lett. 2005, 86, 213114.

43. Staii, C.; Johnson, A. T.; Pinto, N. J.; Nano Lett. 2004, 4, 859.

44. Cury, L. A.; Patrício, P. S. O.; Silva, G. G.; Oliveira, F. A. C.; Righi , A.; Neves, B. R. A.; J. Appl. Phys. 2007, 101, 033133.

45. Zhou, Y.; Freitag, M.; Hone, J.; Staii, C.; Johnson, A. T.; Pinto, N. J.; MacDiarmid, A. G.; Appl. Phys. Lett. 2003, 83, 3800.

Submitted: September 14, 2011

Published online: May 15, 2012 


\title{
Surface Properties of Oxidized and Aminated Multi-Walled Carbon Nanotubes
}

\author{
Wellington M. Silva, ${ }^{a}$ Hélio Ribeiro, ${ }^{a}$ Luciana M. Seara ${ }^{b}$ Hállen D. R. Calado, ${ }^{a}$ \\ André S. Ferlauto, ${ }^{c}$ Roberto M. Paniago, ${ }^{c}$ Cristiano F. Leite ${ }^{c}$ and Glaura G. Silva ${ }^{*, a}$ \\ ${ }^{a}$ Departamento de Química and 'Departamento de Física, Instituto de Ciências Exatas, \\ Universidade Federal de Minas Gerais, 31270-901 Belo Horizonte-MG, Brazil
}

${ }^{b}$ Centro de Microscopia, Universidade Federal de Minas Gerais, 31270-901 Belo Horizonte-MG, Brazil

\section{FTIR spectroscopy}

The absorption band at $1630 \mathrm{~cm}^{-1}$, observed for all samples, is attributed to the $\mathrm{C}=\mathrm{C}$ bond of the hexagonal network in MWCNT. ${ }^{31}$ After the acid oxidation, new bands appear in the FTIR spectra (Figure S1b). The absorption at $1737 \mathrm{~cm}^{-1}$ is attributed to the stretching of the $\mathrm{C}=\mathrm{O}$ bond and the bands from $1460-1380 \mathrm{~cm}^{-1}$ are attributed to the stretching modes of the $\mathrm{C}-\mathrm{O}-\mathrm{H}$ bonds of the carboxylic acid. ${ }^{32,33}$ These contributions confirm the efficiency of the oxidizing process. In the TETA modified MWCNT spectrum (Figure S1c), vibrational modes of the $\mathrm{N}-\mathrm{H}$ bond are observed at $1525 \mathrm{~cm}^{-1}$ and $805-620 \mathrm{~cm}^{-1}$. Another important absorption band is the stretching of the $\mathrm{C}-\mathrm{N}$ bond present in the TETA molecule at $1125 \mathrm{~cm}^{-1}$. The absorption bands from 1460 to $1380 \mathrm{~cm}^{-1}$ are also observed as in the oxidized-MWCNT spectrum. In the region of the spectrum

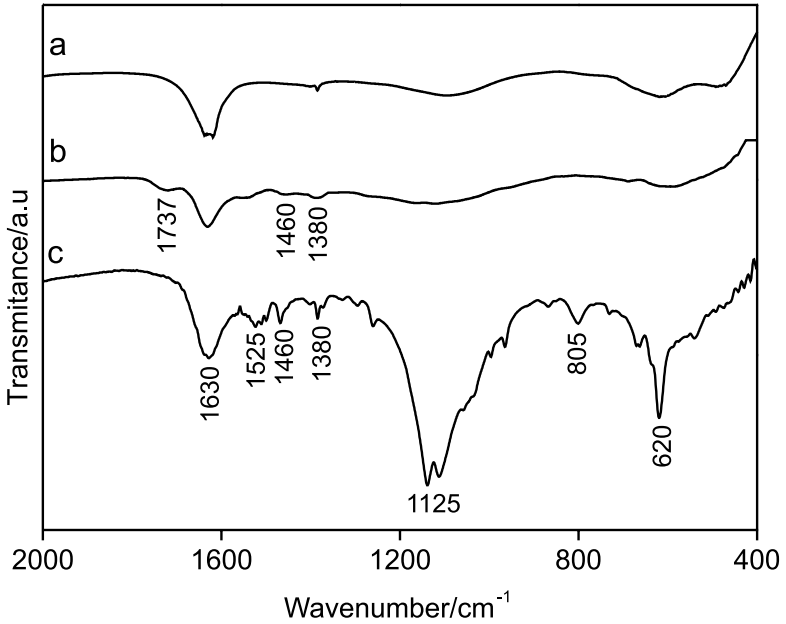

of Figure S1f between 3150 and $2750 \mathrm{~cm}^{-1}$, four bands of low intensity are observed. The first band, formed by a shoulder at $3030 \mathrm{~cm}^{-1}$, and the second at $2965 \mathrm{~cm}^{-1}$ are attributed to the symmetric and asymmetric stretchings of the amide $\mathrm{N}-\mathrm{H}$ bonds $(\mathrm{CONH})$, while the remaining bands at 2930 and $2840 \mathrm{~cm}^{-1}$ are attributed to the symmetric and asymmetric stretchings, respectively, of the methylene group $\left(\mathrm{CH}_{2}\right) \mathrm{C}-\mathrm{H}$ bonds. ${ }^{20}$ The characteristics of this spectrum indicate that the covalent functionalization of MWCNT has likely occurred.

XPS spectroscopy

Figure S2 shows that an increase in the intensity of the $\mathrm{O} 1 \mathrm{~s}$ peak and a decrease in the intensity of the $\mathrm{C}$ 1s peak were verified in comparison with the MWCNT sample after each stage of the chemical processing.

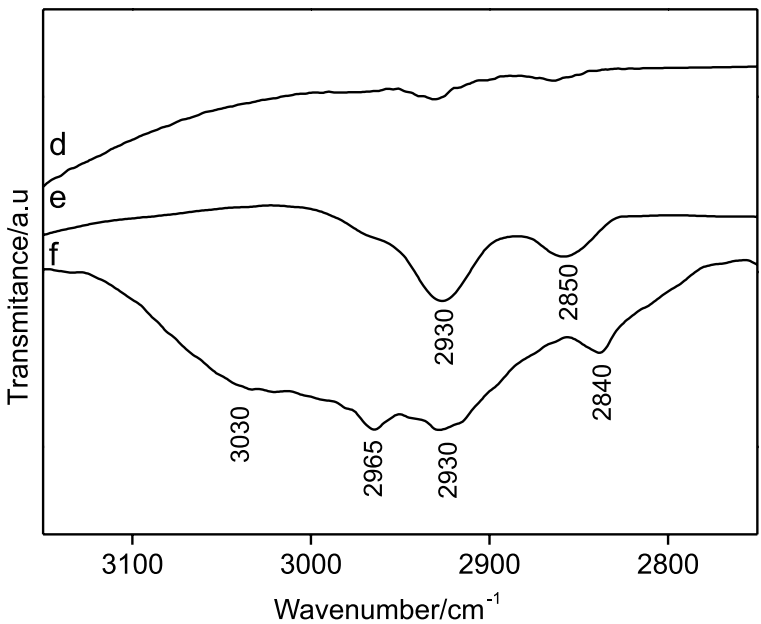

FIGURE S1. Infrared absorption spectra in two spectral regions, between $2000-400 \mathrm{~cm}^{-1}$ and $3150-2750 \mathrm{~cm}^{-1}$ for: a, d) MWCNT; b, e) oxidized-MWCNT; c, f) aminated-MWCNT.

*e-mail: glaura@qui.ufmg.br 


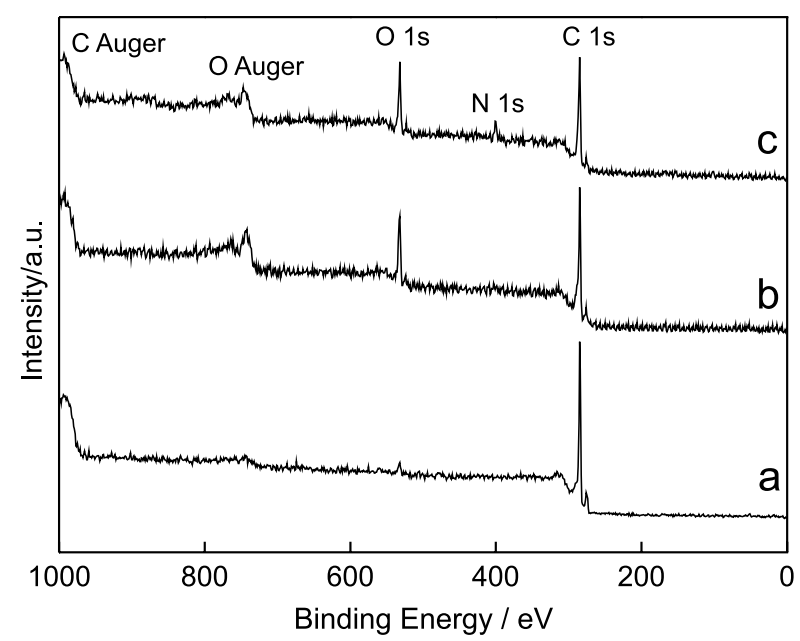

FIGURE S2. XPS spectra for a) MWCNT, b) oxidized-MWCNT and c) aminated-MWCNT samples.

The photoemission $\mathrm{C}$ 1s peaks were studied between 282-292 eV. Figures S3a, S3b and S3c show a dominant peak at $284.5 \mathrm{eV}$ regarding the $\mathrm{sp}^{2}$ hybridized $\mathrm{C}-\mathrm{C}$ bonds in extensive $\pi$-conjugated systems..$^{38} \mathrm{~A}$ secondary peak is verified at $c a .285 .7 \mathrm{eV}$, which is characteristic of $\mathrm{sp}^{3}$ hybridized $\mathrm{C}-\mathrm{C}$ bonds present at defective locations and tubular structure asymmetry. Two additional photoemission peaks are observed at 286.5 and $287.9 \mathrm{eV}$ (Figure S3a,
$\mathrm{S} 3 b)$. The first is attributed to carbon atoms bonded to oxygen atoms $(-\mathrm{C}-\mathrm{O}-\mathrm{R})$, and the second is characteristic of carbon atoms pertaining to carbonyl groups $(-\mathrm{C}=\mathrm{O}) .{ }^{39}$ At $291.0 \mathrm{eV}$, a satellite peak is observed, which is caused by the $\pi-\pi *$ electronic transition. ${ }^{21}$ The evidence of carboxylic groups presence is obtained by the observation of a peak at $288.8 \mathrm{eV}$ (Figure S3b), which is typical for this functional group. ${ }^{39}$ Figure $\mathrm{S} 3 \mathrm{c}$ shows the presence of carbon at $-\mathrm{N}-\mathrm{C}=\mathrm{O}$ bond with absorption at $287.6 \mathrm{eV}$. This observation of carbon in the amide group shows the efficiency of the covalent functionalization of MWCNT with TETA.

The adjustments of the peak of photoemission for $\mathrm{O}$ $1 \mathrm{~s}$ in the case of the MWCNT spectrum are shown in Figure S3d. There are two peaks at 527.7 and $529.9 \mathrm{eV}$, associated with oxygen atoms bonded to metallic particles $\left(\mathrm{Al}_{2} \mathrm{O}_{3}\right.$ and $\left.\mathrm{Fe}_{2} \mathrm{O}_{3}\right)$, that can be related to the synthetic process. Peaks at 534.4 and $535.7 \mathrm{eV}$ can be assigned to the $\mathrm{O}-\mathrm{H}$ bond of water, which along with the other peaks in Figure S3d are associated with oxygen-containing functional groups adsorbed on the surface of the tubes. After the chemical process, peaks related to the $-\mathrm{C}-\mathrm{O}$ bond are observed at $531.6 \mathrm{eV}$ (Figure $\mathrm{S} 3 \mathrm{e}$ ) and $531.8 \mathrm{eV}$ (Figure $\mathrm{S} 3 \mathrm{f}$ ), and those related to the $-\mathrm{C}=\mathrm{O}$ bond appear at $533.2 \mathrm{eV}$ (Figure S3e) and at $533.8 \mathrm{eV}$ (Figure S3f). ${ }^{21}$ 

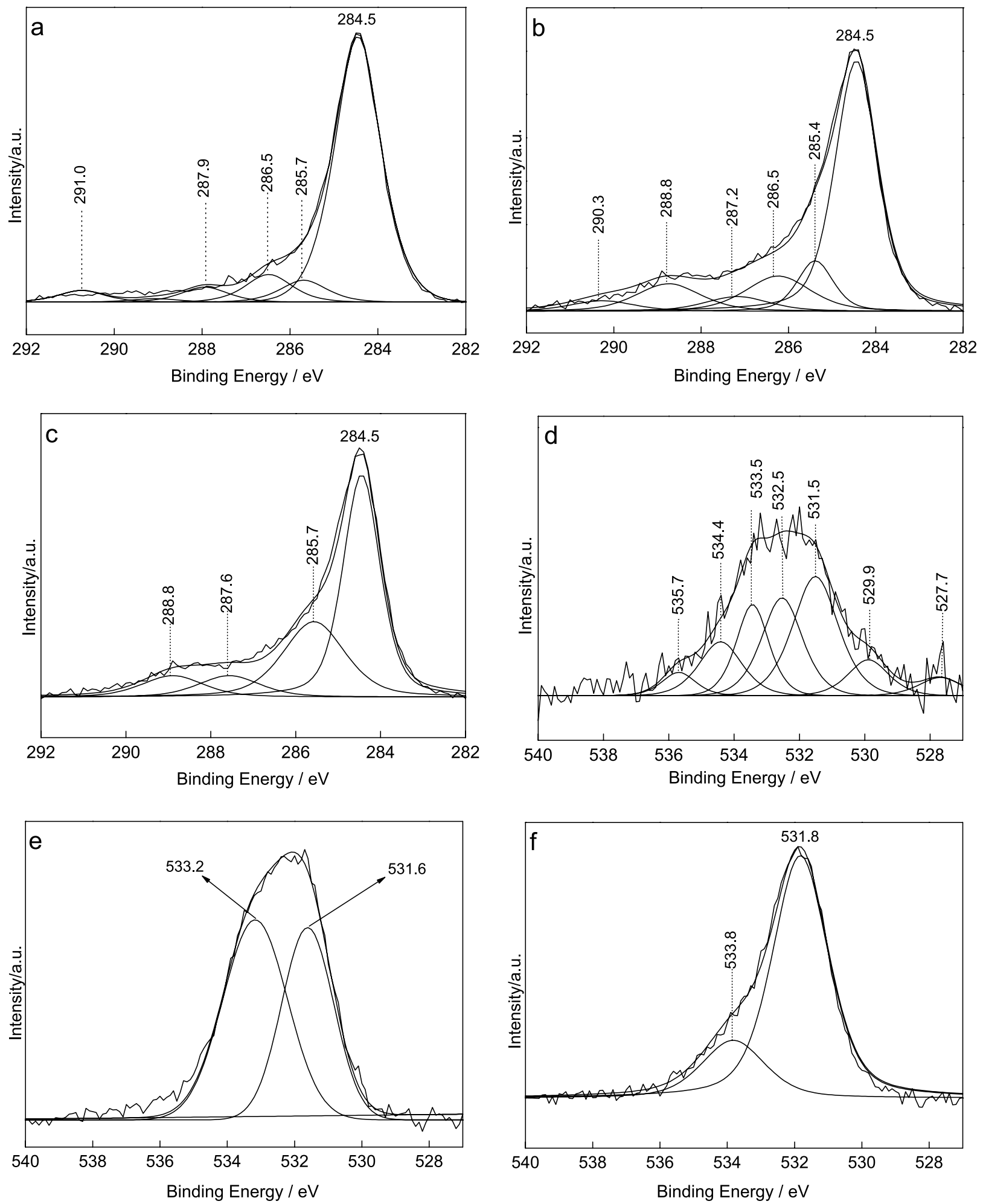

FIGURE S3. High resolution XPS spectra obtained in the C 1s bonding energy region for a) MWCNT, b) oxidized-MWCNT and c) aminated-MWCNT. Signals for O 1s in d) MWCNT, e) oxidized-MWCNT and f) aminated-MWCNT samples are also shown. 